\title{
Correction to: Building an efficient OCR system for historical documents with little training data
}

Jiří Martínek ${ }^{1} \cdot$ Ladislav Lenc ${ }^{2} \cdot$ Pavel Král ${ }^{1,2}$

Published online: 10 March 2021

(C) Springer-Verlag London Ltd., part of Springer Nature 2021

\section{Correction to: Neural Computing} and Applications (2020) 32:17209-17227 https://doi.org/10.1007/s00521-020-04910-x

The article [Building an efficient OCR system for historical documents with little training data], written by [Jiří Martínek, Ladislav Lenc and Pavel Král], was originally published electronically on the publisher's Internet portal (currently SpringerLink) on [9th May 2020] without open access. With the author(s)' decision to order Open Choice, the copyright of the article changed on 3rd December 2020 to (C) [The Authors] [2020] and the article is forthwith distributed under the terms of copyright.

Publisher's Note Springer Nature remains neutral with regard to jurisdictional claims in published maps and institutional affiliations.

The original article can be found online at https:// doi.org/10.1007/s00521-020-04910-x.

Pavel Král

pkral@kiv.zcu.cz

Jiří Martínek

jimar@kiv.zcu.cz

Ladislav Lenc

llenc@kiv.zcu.cz

1 Department of Computer Science and Engineering, Faculty of Applied Sciences, University of West Bohemia, Plzeň, Czech Republic

2 NTIS - New Technologies for the Information Society, Faculty of Applied Sciences, University of West Bohemia, Plzeň, Czech Republic 